\title{
Endoscopic treatment of chronic pancreatitis: European Society of Gastrointestinal Endoscopy (ESGE) Guideline - Updated August 2018
}

\section{(3) \\ ESGE}

\section{Authors}

Jean-Marc Dumonceau' ${ }^{1}$, Myriam Delhaye ${ }^{2}$, Andrea Tringali3,4, Marianna Arvanitakis², Andres Sanchez-Yague ${ }^{5}$, Thierry Vaysse ${ }^{6}$, Guruprasad P. Aithal7 ${ }^{7}$, Andrea Anderloni ${ }^{8}$, Marco Bruno ${ }^{9}$, Paolo Cantú ${ }^{10}$, Jacques Devière ${ }^{2}$, Juan Enrique Domínguez-Muñoz ${ }^{11}$, Selma Lekkerkerker ${ }^{12}$, Jan-Werner Poley ${ }^{9}$, Mohan Ramchandani ${ }^{13}$, Nageshwar Reddy ${ }^{13}$, Jeanin E. van Hooft ${ }^{12}$

Institutions

1 Gedyt Endoscopy Center, Buenos Aires, Argentina

2 Department of Gastroenterology Hepatopancreatology, and Digestive Oncology, Erasme University Hospital, Université Libre de Bruxelles, Brussels, Belgium

3 Digestive Endoscopy Unit, Fondazione Policlinico Universitario Agostino Gemelli, IRCCS, Rome, Italy

4 Centre for Endoscopic Research, Therapeutics and Training (CERTT), Università Cattolica del Sacro Cuore, Rome, Italy

5 Gastroenterology and Hepatology, Hospital Costa del Sol, Marbella, Spain

6 Service de Gastroentérologie, University Hospital of Bicêtre, Assistance Publique-Hopitaux de Paris, Université Paris Sud, Le Kremlin Bicêtre, France

7 Nottingham Digestive Diseases Centre, NIHR Nottingham Biomedical Research Centre, Nottingham University Hospitals NHS Trust and University of Nottingham, UK

8 Endoscopy Unit, IRCCS Istituto Clinico Humanitas, Rozzano, Milan, Italy

9 Department of Gastroenterology and Hepatology, Erasmus University Medical Center, Rotterdam, The Netherlands

10 Gastroenterology and Endoscopy Unit, Fondazione IRCCS Ca' Granda Ospedale Maggiore Policlinico, Department of Pathophysiology and Transplantation, Università degli Studi di Milano, Milan, Italy

11 Gastroenterology Department, University Hospital of Santiago de Compostela, Santiago de Compostela, Spain

12 Department of Gastroenterology and Hepatology, Amsterdam UMC, University of Amsterdam, The Netherlands

13 Asian Institute of Gastroenterology, Hyderabad, India
Bibliography

DOI https://doi.org/10.1055/a-0822-0832

Published online: 17.1.2019 | Endoscopy 2019; 51: 179-193

(c) Georg Thieme Verlag KG Stuttgart · New York

ISSN 0013-726X

Corresponding author

Jean-Marc Dumonceau, MD PhD, Gedyt Endoscopy Center, Beruti 2347 (C1117AAA), Buenos Aires, Argentina

Fax: +54-11-5288-6100

jmdumonceau@hotmail.com

\# Appendix 1s, Tables 1s-8s

Online content viewable at:

https://doi.org/10.1055/a-0822-0832

\section{MAIN RECOMMENDATIONS}

ESGE suggests endoscopic therapy and/or extracorporeal shockwave lithotripsy (ESWL) as the first-line therapy for painful uncomplicated chronic pancreatitis $(\mathrm{CP})$ with an obstructed main pancreatic duct (MPD) in the head/body of the pancreas. The clinical response should be evaluated at 6 - 8 weeks; if it appears unsatisfactory, the patient's case should be discussed again in a multidisciplinary team and surgical options should be considered.

Weak recommendation, low quality evidence.

ESGE suggests, for the selection of patients for initial or continued endoscopic therapy and/or ESWL, taking into consideration predictive factors associated with a good long-term outcome. These include, at initial work-up, absence of MPD stricture, a short disease duration, non-severe pain, absence or cessation of cigarette smoking and of alcohol intake, and, after initial treatment, complete removal of obstructive pancreatic stones and resolution of pancreatic duct stricture with stenting.

Weak recommendation, low quality evidence.

ESGE recommends ESWL for the clearance of radiopaque obstructive MPD stones larger than $5 \mathrm{~mm}$ located in the head/body of the pancreas and endoscopic retrograde 
cholangiopancreatography (ERCP) for MPD stones that are radiolucent or smaller than $5 \mathrm{~mm}$.

Strong recommendation, moderate quality evidence.

ESGE suggests restricting the use of endoscopic therapy after ESWL to patients with no spontaneous clearance of pancreatic stones after adequate fragmentation by ESWL. Weak recommendation, moderate quality evidence.

ESGE suggests treating painful dominant MPD strictures with a single 10-Fr plastic stent for one uninterrupted year if symptoms improve after initial successful MPD drainage. The stent should be exchanged if necessary, based on symptoms or signs of stent dysfunction at regular pancreas imaging at least every 6 months. ESGE suggests consideration of surgery or multiple side-by-side plastic stents for symptomatic MPD strictures persisting beyond 1 year after the initial single plastic stenting, following multidisciplinary discussion.

Weak recommendation, low quality evidence.
ESGE recommends endoscopic drainage over percutaneous or surgical treatment for uncomplicated chronic pancreatitis (CP)-related pseudocysts that are within endoscopic reach.

Strong recommendation, moderate quality evidence.

ESGE recommends retrieval of transmural plastic stents at least 6 weeks after pancreatic pseudocyst regression if MPD disruption has been excluded, and long-term indwelling of transmural double-pigtail plastic stents in patients with disconnected pancreatic duct syndrome.

Strong recommendation, low quality evidence.

ESGE suggests the temporary insertion of multiple side-byside plastic stents or of a fully covered self-expandable metal stent (FCSEMS) for treating CP-related benign biliary strictures.

Weak recommendation, moderate quality evidence.

ESGE recommends maintaining a registry of patients with biliary stents and recalling them for stent removal or exchange.

Strong recommendation, low quality evidence.

\section{PUBLICATION INFORMATION}

This Guideline is an official statement of the European Society of Gastrointestinal Endoscopy (ESGE). It addresses the indications for, techniques, and results of treatment of chronic pancreatitis by extracorporeal shockwave lithotripsy and/or endoscopy.

\section{Introduction}

The Clinical Guideline on the endoscopic treatment of chronic pancreatitis (CP) published in 2012 by the European Society of Gastrointestinal Endoscopy (ESGE) made recommendations on the indications and modalities of treatment for CP [1]. New evidence has become available since then and is discussed in the present update, and new recommendations are issued.

\section{Methods}

ESGE commissioned this Guideline and appointed a Guideline leader (J.M.D.) who invited the listed authors to participate in the project development. The key questions were prepared by the coordinating team (J.M.D., A.T., M.D.) and then approved by the other members. The coordinating team formed task force subgroups, each with its own leader, who was assigned key questions (see Appendix $1 \mathrm{~s}$, online-only Supplementary Material).

Each task force performed a systematic literature search to prepare evidence-based and well-balanced statements on their assigned key questions. The literature search was performed using MEDLINE and Embase to identify new publications since January 2012 published in English. The Grading of Recommen-

ABBREVIATIONS
$\begin{array}{ll}\text { CP } & \text { chronic pancreatitis } \\ \text { ERCP } & \text { endoscopic retrograde cholangiopancreato- } \\ \text { graphy }\end{array}$
$\begin{array}{ll}\text { ESGE } & \text { European Society of Gastrointestinal Endoscopy } \\ \text { ESWL } & \text { extracorporeal shockwave lithotripsy } \\ \text { FCSEMS fully covered self-expandable metal stent } \\ \text { LAMS } & \text { lumen-apposing metal stent } \\ \text { MPD } & \text { main pancreatic duct } \\ \text { MRCP } & \text { magnetic resonance cholangiopancreatography } \\ \text { MRI } & \text { magnetic resonance imaging } \\ \text { OR } & \text { odds ratio } \\ \text { PFC } & \text { pancreatic fluid collection } \\ \text { PPC } & \text { pancreatic pseudocyst } \\ \text { RR } & \text { relative risk } \\ \text { RCT } & \text { randomized controlled trial } \\ \text { SEMS } & \text { self-expandable metal stents } \\ \text { S-MRCP secretin-enhanced magnetic resonance } & \\ & \text { cholangiopancreatography }\end{array}$

dations Assessment, Development and Evaluation (GRADE) system was adopted to define the strength of recommendation and the quality of evidence [2]. Each task force proposed statements on their assigned key questions which were discussed during a meeting in Brussels, Belgium, in June 2017. Literature searches were re-run in August 2018. This time-point should be the starting point in the search for new evidence for future updates to this Guideline. In August 2018 a draft prepared by J.M.D. was sent to all group members for review. The draft was also reviewed by two members of the ESGE Governing Board, by external reviewers, and by the ESGE National Societies and 
Individual Members. After agreement on a final version, the manuscript was submitted to the journal Endoscopy for publication. All authors agreed on the final revised version.

This Guideline was issued in 2018 and will be considered for review in 2022, or sooner if new and relevant evidence becomes available. Any updates to the Guideline in the interim period will be noted on the ESGE website: https://www.esge. com/esge-guidelines.html.

\section{Choice of treatment and initial work-up}

\section{RECOMMENDATION}

ESGE suggests endoscopic therapy and/or extracorporeal shockwave lithotripsy (ESWL) as the first-line therapy for painful uncomplicated chronic pancreatitis (CP) with an obstructed main pancreatic duct (MPD) in the head/ body of the pancreas. The clinical response should be evaluated at 6-8 weeks; if it appears unsatisfactory, the patient's case should be discussed again in a multidisciplinary team and surgical options should be considered. Weak recommendation, low quality evidence.

The first step proposed to relieve pain in patients with uncomplicated CP includes lifestyle modifications plus, in selected patients, endoscopic therapy and/or ESWL [3]. If endoscopic therapy and/or ESWL provide no persistent pain relief or technically fail, or if the patient is not a good candidate for endoscopic therapy and/or ESWL, medical treatment including analgesics and adjunctive agents (e.g., pharmaceutical agents aimed to relieve neuropathic pain) are proposed, with the final step being early surgery for nonresponders. In a large prospective multicenter U.S. cohort $(n=521)$, medical therapy, endoscopic therapy, and pancreatic surgery were performed in 69\%, 52\%, and $18 \%$ of patients, respectively [4]. Similarly, in 33 series of CP patients treated with endoscopic therapy and/or ESWL, surgery was performed during long-term follow-up in a minority of patients, less frequently in those with stones as the main obstructing factor (117 of 1695 [6.9\%], 13 series, Table 1 s, see Supplementary Material, online-only) as compared to those with strictures (157 of 1061 patients [14.8\%], 20 series, Table $2 \mathrm{~s} ; P<0.001)$.

Two trials have suggested that surgery was superior to endoscopic therapy and/or ESWL for pain relief [5-7]. In the first trial [5], pain was absent after 5 years of follow-up in $15 \%$ vs. $34 \%$ of patients treated with endoscopic therapy vs. surgery, respectively, showing that neither of these options is entirely satisfactory. Furthermore, neither ESWL nor cumulative stenting were used and the randomized design of the study is questionable. In the other trial [6, 7], only 39 patients were included; all of them had advanced CP and most were opioid-dependent. For these reasons, the results cannot be extrapolated to all patients with CP. A cost - effectiveness model based on data of this randomized controlled trial (RCT) unsurprisingly concluded that surgery was more effective and less costly than endoscopic therapy in CP [8], but another RCT has shown that ESWL could provide satisfactory clinical results at a relatively low cost in patients with obstructive stones in the main pancreatic duct (MPD) (62\% of patients with no pain relapse at 4-year followup after ESWL) [9]. Finally, a retrospective study (86 CP patients) reported similar pain relief 5.4 years after endoscopic therapy and/or ESWL vs. surgery, but surgery carried more complications and higher costs [10].

Endoscopic therapy and/or ESWL aim to relieve an obstruction in the MPD. They are proposed only to patients with marked ductal changes, mainly dilation, corresponding to the most severe grade in the Cambridge classification of pancreatitis [11]. No recent publications have reported the results of endoscopic therapy in patients with less severe changes [1213]. In painless $C P$, endoscopic therapy and/or ESWL are not performed because the only potential benefit (preserving the pancreatic function) is uncertain: a single prospective nonrandomized comparative study examined this in $42 \mathrm{CP}$ patients and found that the mean value of the N-benzoyl-L-tyrosyl para-aminobenzoic acid test was higher at 5-year follow-up after stenting vs. no stenting of a MPD stricture while no differences were observed for overt diabetes [14]. These results have not been confirmed and in most long-term studies the pancreatic function deteriorated during follow-up [15-19].

\section{RECOMMENDATION}

ESGE suggests, for the selection of patients for initial or continued endoscopic therapy and/or ESWL, taking into consideration predictive factors associated with a good long-term outcome. These include, at initial work-up, absence of MPD stricture, a short disease duration, a short disease duration, non-severe pain, absence or cessation of cigarette smoking and of alcohol intake, and, after initial treatment, complete removal of obstructive pancreatic stones and resolution of pancreatic duct stricture with stenting.

Weak recommendation, low quality evidence.

During the pretherapeutic evaluation of a patient, factors associated with a good long-term clinical outcome may help to select patients for endoscopic therapy and/or ESWL. These factors should be considered as orientative only as the differences in the proportions of patients with long-term success for an individual factor are small. The factors include absence of MPD stricture (see above) as well as short disease duration, non-severe pain (including low dose use of narcotics), the absence or cessation of cigarette smoking and of alcohol intake, cephalic location of stones, the absence of pancreas divisum if MPD stenting is required, and steatorrhea $(4,4,3,2,1,1$, and 1 studies, respectively) (Table $3 \mathbf{s}$ ). Favorable prognostic factors related to endoscopic therapy and/or ESWL include complete stone removal and MPD stricture resolution after stenting (2 and 1 studies, respectively). 
Patients with an MPD obstruction located only in the tail of the pancreas are not considered candidates for ESWL and/or endoscopic therapy by some groups of authors [20].

\section{RECOMMENDATION}

ESGE suggests performing a high quality pancreatic computed tomography (CT) scan and/or magnetic resonance imaging with cholangiopancreatography to reasonably rule out pancreatic cancer and to plan treatment in patients with chronic pancreatitis.

Weak recommendation, low quality evidence.

The risk of pancreatic cancer is increased in patients with $C P$, particularly in the first years following diagnosis [21]. A metaanalysis (52 studies, 5399 patients) found that endoscopic ultrasonography (EUS), CT scan, and magnetic resonance imaging (MRI) present similar diagnostic accuracies for the diagnosis of pancreatic cancer [22]. Imaging methods of the pancreas are constantly refined and they are often used in combination $[23,24]$. In the particular context of CP, MRI with diffusionweighted imaging has shown sensitivity and specificity for the diagnosis of malignancy of $86 \%$ and $82 \%$, respectively, in a meta-analysis [25], while EUS-guided sampling seems to be less sensitive according to a retrospective and a prospective study (54\% and $74 \%$ vs. $89 \%$ and $91 \%$ in the presence vs. the absence of CP, respectively) [26,27]. The yield of EUS elastography and contrast-enhanced harmonic EUS as well as methods to improve the accuracy of EUS-guided sampling are discussed in dedicated ESGE Guidelines [28, 29].

Non-contrast CT scan accurately delineates calcified stones in the pancreas and allows measurement of stone density, a factor associated with the completeness of stone extraction [30]. Contrast enhancement may help to locate stones relative to the ducts [31,32]. Magnetic resonance cholangiopancreatography (MRCP) identifies ductal abnormalities; in two retrospective studies its diagnostic accuracy for ductal abnormalities was $73.2 \%$ (41 children with CP) and 92.2\% (30 adults with CP) $[33,34]$.

\section{Pancreatic stone management}

Pancreatic stones seem to arise as either direct and evenly calcified stones or as radiolucent protein plugs that may or may not become calcified during the course of the disease [35]. The vast majority of pancreatic stones are calcified and radiopaque; their prevalence increases with time to reach $50 \%$ and $100 \%$, at 5 and 14 years after the onset of the disease, approximately [36]. In a multicenter survey (879 CP patients with a mix of newly diagnosed and long-standing disease), calcified pancreatic stones were detected in $62 \%$ of patients; they were more frequent in men, heavy drinkers (>80 g/day), and heavy smokers ( $\geq 20$ cigarettes/day) [37]. Pancreatic stones in CP patients who undergo endoscopic therapy and/or ESWL are solitary in $10 \%-62 \%$ of patients; they are most frequently located in the pancreatic head only, with a mean size of $10 \mathrm{~mm}$, and they are associated with strictures in approximately $50 \%$ of patients (Table $\mathbf{4 s}$ ).

Successful stone fragmentation following ESWL has been defined as stones broken into fragments $\leq 2$ or $3 \mathrm{~mm}$, or by the demonstration at X-ray of decreased stone density, increased stone surface, and heterogeneity of the stone which may fill the MPD and adjacent side branches [38]. Ductal clearance has been defined as complete, partial, or unsuccessful if the proportion of stones cleared was $>90 \%, 50 \%-90 \%$, or $<50 \%$, respectively [39].

\section{RECOMMENDATION}

ESGE recommends ESWL for the clearance of radiopaque obstructive MPD stones larger than $5 \mathrm{~mm}$ located in the head/body of the pancreas, and endoscopic retrograde cholangiopancreatography (ERCP) for MPD stones that are radiolucent or smaller than $5 \mathrm{~mm}$.

Strong recommendation, moderate quality evidence.

Endoscopy alone, using pancreatic sphincterotomy and a basket or a balloon, allows stone extraction in a minority of CP patients: $9 \%$ of 1041 patients in two retrospective series [ 40 41] and $14 \%$ of 1834 patients in a survey of 125 hospitals [42]. Failed stone extraction using these techniques is associated with stones $>10 \mathrm{~mm}$, diffuse location, stone impaction, and location upstream from a stricture [41,43]. Furthermore, pancreatic mechanical lithotripsy carries a complication rate threefold higher compared with biliary mechanical lithotripsy according to a retrospective study of 712 patients [44]. Complications in the 69 patients with pancreatic stones included trapped or broken basket, traction wire fracture, and one pancreatic ductal leak which required surgery [44]. In one of the abovementioned series, ESWL allowed the endoscopic extraction of pancreatic stones in $>80 \%$ of the patients after failed stone extraction at primary endoscopy [40]. Similarly, a retrospective study (70 patients) found that performance of ESWL prior to the endoscopic attempt at stone extraction was the only independent factor associated with successful stone clearance [45]. Therefore, a primary endoscopic attempt at pancreatic stone extraction is reserved to selected patients, based on a reasonable expectation of success or on technical difficulty in performing ESWL as with radiolucent stones or stones $<5 \mathrm{~mm}$ that are difficult to target using $\mathrm{X}$-rays.

A meta-analysis (27 studies including 6 prospective ones, in total 3189 patients with pancreatic stones $>5 \mathrm{~mm}$ ) reported that pancreatic ESWL allowed complete/partial MPD clearance in $70 \% / 22 \%$ of patients, respectively, that pain was absent or mild-moderate during the 2 years following treatment in $52.7 \%$ and $33.4 \%$ of patients, respectively, and that quality of life improved after ESWL in $88.2 \%$ of patients [39]. ERCP was combined with ESWL in most studies. Table $1 \mathrm{~s}$ summarizes the outcomes of ESWL alone or combined with endoscopic stone extraction. Pain relapsed in $30 \%-50 \%$ of patients dur- 
ing a follow-up of $1-14$ years and surgery was performed in $6.9 \%$ of patients. Of note, the studies that reported the timing of pain relapse showed that patients with no pain relapse at 2-year follow-up rarely experience pain relapse thereafter $[9,16,45]$, in particular if stone clearance has been complete [30]. Approximately half of patients with relapsing pain present with stone recurrence [46].

\section{RECOMMENDATION}

ESGE suggests restricting the use of endoscopic therapy after ESWL to patients with no spontaneous clearance of pancreatic stones after adequate fragmentation by ESWL. Weak recommendation, moderate quality evidence.

The addition of endoscopic therapy to ESWL provided no additional benefit in two studies that compared ESWL vs. ESWL systematically combined with endoscopic therapy $[9,47]$. An RCT (55 patients) of ESWL alone vs. ESWL combined with endoscopic therapy reported similar decreases in MPD diameter and in number of pain episodes/year; patients who had ESWL combined with endoscopic therapy had a longer hospital stay and higher treatment costs [9]. Furthermore, a retrospective series (146 patients) found no differences in pain resolution 6 months after ESWL alone vs. combined with endoscopic therapy; the criteria for performing endoscopic therapy or not were not stated [47].

The first case series of ESWL alone for pancreatic stones was reported in 1996 from Japan; it reported pain relief in 22 of 28 patients (79\%) at 44-month follow-up [48]. Three surveys of the treatment of pancreatic stones in Japanese hospitals during 5-year periods were reported in 2018 (125 hospitals, 1834 patients), 2013 (34 hospitals, 916 patients) and 2005 (11 hospitals, 555 patients) $[41,42,49]$. The rates of spontaneous stone clearance after ESWL were $15 \%, 49 \%$, and $70 \%$, respectively, and the proportions of patients who had endoscopic therapy after ESWL were $81 \%, 56 \%$, and $43 \%$, respectively. The inclusion of a greater number of less specialized hospitals in the most recent survey might explain these differences [42]. In all of these studies, no differences in baseline characteristics of patients who had ERCP alone or combined with ERCP were reported except for gender in one study [47].

\section{ESWL: technical factors, complications and contraindications}

Pancreatic stone fragmentation is obtained after ESWL in approximately $90 \%$ of patients [50]; this may require multiple ESWL sessions (up to 8 in a large series with a high rate of successful fragmentation) [20]. More shockwaves may be required for stones that are larger [51], multiple [52], or associated with a MPD stricture [53], while pancreatic stenting prior to ESWL seems to decrease the number of shockwaves and of ESWL sessions required [51]. Multicenter surveys have suggested that stone fragmentation is less frequently successful in low case volume centers while the role of the type of lithotripter has been controversial $[41,42,49]$.

After ESWL, endoscopic clearance of stone fragments has been more frequently successful with solitary stones $[17,20$, $30,45,53]$, stones located in the pancreatic head [20], stones with a density at CT scan of $<820.5$ Hounsfield units [30], if a pancreatic stent had been inserted prior to ESWL $[54,55]$, if secretin had been administered at the beginning of ESWL [55], and if ERCP was delayed by more than 2 days after ESWL [56]. Pancreatic pseudocysts (PPCs) did not affect stone clearance or adverse events in a prospective series of 849 patients (59 with a PPC) [57].

The most frequent complication of ESWL is pancreatitis; it has been reported in $4.2 \%$ of the patients in a meta-analysis, but most of the included studies were retrospective and did not allow the attribution of complications to either endoscopic therapy or ESWL as both were performed in most patients [39]. In a prospective study (634 patients, 1470 ESWL sessions), transient adverse events (asymptomatic hyperamylasemia, hematuria, gastrointestinal mucosal injury) and complications were detected in $21.2 \%$ and $6.7 \%$ of the procedures, respectively [58]. Complications included pancreatitis, infection, steinstrass (acute stone incarceration in the papilla), bleeding, and perforation; they were classified as moderate or severe in $1.1 \%$ of the cases. Skin erythema and tenderness in the region in contact with the shockwave head were noted in most patients [58].

Contraindications to ESWL include non-correctable coagulation disorders, pregnancy, and presence in the shockwave path of bone, calcified vessels, or lung tissue [59]. Specific precautions should be taken for patients with implantable defibrillators and pacemakers [60].

\section{RECOMMENDATION}

ESGE suggests considering pancreatoscopy-guided lithotripsy when ESWL is not available or for stones that were not fragmented after adequately performed ESWL.

Weak recommendation, low quality evidence.

Reports of intracorporeal lithotripsy using electrohydraulic or laser lithotripsy under peroral pancreatoscopy are sparse. A systematic review (10 studies, 87 patients) reported successful MPD clearance in $43 \%-100 \%$ of patients [61]. Results may be biased as the reports included selected patients with anatomical features thought to permit passage of the pancreatoscope to the target stone in a stable position. The largest study reported complete and partial stone clearance in 24 (63\%) and 10 (26\%) of 38 patients, respectively, after a total of 280 endoscopic therapy sessions, including 88 with pancreatoscopy; complications (post-ERCP pancreatitis and one perforation) were reported for 20 procedures and the overall clinical success rate was $74 \%$ [62]. 


\section{Pancreatic strictures}

Since the previous publication of this Guideline no new definitions of the types of MPD strictures in CP have been reported. Besides benign vs. malignant and single vs. multiple, strictures may be classified as either non-dominant or dominant [63]. Dominant MPD strictures are defined by the presence of at least one of the following characteristics: upstream MPD dilatation $\geq 6 \mathrm{~mm}$ in diameter, prevention of contrast medium outflow alongside a 6 - $\mathrm{Fr}$ catheter inserted upstream from the stricture, or abdominal pain during continuous infusion of a nasopancreatic catheter inserted upstream from the stricture with $1 \mathrm{~L}$ saline for $12-24 \mathrm{~h}$.

Stent insertion across a dominant MPD stricture (or the most proximal [tail] one in the case of multiple strictures) defines technical success. It aims to: (i) decompress the MPD, thereby ameliorating pain, and (ii) persistently dilate the stricture(s). Less frequent indications include facilitation of MPD stone clearance in association with ESWL as detailed above, and to bypass an obstruction in the ventral duct by inserting a stent through the minor papilla into the MPD [64]. A prospective non-randomized study showed in 42 patients with a dominant MPD stricture that pain recurred less frequently in patients who had received a temporary pancreatic stenting vs. those who had not (15\% vs. $50 \%$ during a 5 -year follow-up) [14]. Before stent dilation therapy is embarked upon, malignancy should be reasonably excluded, for example by brush cytology and cross-sectional imaging (see Section 3).

Refractory MPD strictures are defined as symptomatic dominant strictures that persist or relapse after 1 year of single pancreatic stent placement. A validated short-term definition for clinical success is still lacking. For long-term evaluation, the absence of pain during the year following stent removal still seems a reasonable and workable definition.

\section{RECOMMENDATION}

ESGE suggests treating painful dominant MPD strictures with a single 10-Fr plastic stent for one uninterrupted year if symptoms improve after initial successful MPD drainage. The stent should be exchanged if necessary, based on symptoms or signs of stent dysfunction at regular pancreas imaging at least every 6 months. ESGE suggests consideration of surgery or multiple side-by-side plastic stents for symptomatic MPD strictures persisting beyond 1 year after the initial single plastic stenting, following multidisciplinary discussion.

Weak recommendation, low quality evidence.

Insertion of a single plastic stent has been used as the initial endoscopic therapy for MPD strictures (Table $2 \mathrm{~s}$ ); these strictures were single in $>80 \%$ of the patients [65-66], and some studies explicitly excluded patients with multiple strictures [67]. After temporary insertion of a single plastic stent in the MPD, stricture resolution was achieved in $9 \%$ [68] to $50 \%$ [6] of 145 patients in five studies $[6,67-70]$ but this is not requir- ed for long-term pain relief [67]. Long-term pain relief was reported in $67.5 \%$ of 536 patients $(95 \%$ confidence interval $[\mathrm{Cl}]$ $51.5 \%-80.2 \%$ ) in a meta-analysis of 9 studies [71]. The followup duration after stent removal was not calculated but in most studies it was $\geq 24$ months, the period during which almost all pain relapses occur $[6,14,66,70,72-74]$.

Refractory strictures may be treated by surgery, multiple side-by-side plastic stents (Table $5 \mathrm{~s}$ ), or self-expandable metal stents (SEMSs) (Table 6 s).

The temporary insertion of multiple side-by-side plastic stents in 48 patients yielded stricture resolution and pain relief at 9.5 -year follow-up in $89.5 \%$ and $77.1 \%$ of the patients, respectively [75-76].

With respect to SEMSs, uncovered and partially covered types have provided disappointing results [77] but temporary placement of a fully covered SEMS (FCSEMS) has provided pain improvement in $85 \%$ of patients according to a systematic review of four prospective series (total 61 patients) [78]. These studies were limited by a very short follow-up, and three more recent studies $(n=41)$ have reported pain improvement in $37 \%-88 \%$ of patients during a follow-up of $3-4$ years [7981]. Pancreatic FCSEMS need further evaluation in the setting of clinical trials because of potential complications as listed below.

\section{Pancreatic stenting: technical factors and complications}

Whether or not a pancreatic sphincterotomy should be performed before pancreatic stent insertion has not been addressed in any study, but both methods have been reported for the insertion of a single plastic stent as well as for a SEMS $[18,65$, $79,82-85]$. With respect to the performance of a biliary sphincterotomy prior to pancreatic sphincterotomy, this should only be performed in selected cases, according to a small RCT, mostly if biliary drainage is indicated or to facilitate access to the MPD [86].

In many but not all studies $[51,54,55]$, pancreatic stenting was performed after stone fragmentation and removal. In prospective series, technical success was reported in $92 \%$ of attempted insertions of a first stent $[6,14,67,87]$. The stenting duration averaged 10.6 months (range $3.2-23$ months) in 18 series totaling 811 patients [5,6,14,64-67,70,72-74,82, $87-92]$.

Multiple stent designs have been proposed, including straight, S-shaped, and winged stents, and stents with or without sideholes [93-94]. Few comparative studies have been reported; in a prospective study, stents with large sideholes have been suggested to occlude less frequently compared to other types, but only a minority of patients had CP [95]. With respect to stent diameter, CP patients treated with stents $\leq 8.5$ - $\mathrm{Fr}$ were 3.2 times more likely to be hospitalized for abdominal pain than those who had received $10-\mathrm{Fr}$ stents in a retrospective study of 163 CP patients [96].

"On-demand" stent exchange consists of exchanging pancreatic stents when deemed necessary, based on patient symptoms and/or additional investigations at 1-6-month intervals (i. e., secretin-enhanced MRCP [S-MRCP] [66], abdominal ultra- 
sound alone [68] or supplemented either with abdominal plain film [66] or with blood/urinary amylase measurements [69]). With this stent exchange policy, sepsis of pancreatic origin was reported in 15 (5.2\%) of 288 patients in four series [66, 68-69, 72 ] and surgery was required in two patients for pancreatic abscesses; this was reported in the only series in which no additional investigations at regular intervals were performed [72]. On the other hand, in 12 series (521 patients) with stent exchange scheduled at shorter intervals, usually 3 months, septic complications have not been reported $[5,14,65,67,70,73,74$, $88,90,92,97,98]$.

Compared with surgery, hospital stays and medical expenses were similar for patients who had pancreatic stenting for less than 1 year $(n=19)$ but higher for those who required longer pancreatic stenting $(n=15)$, in a retrospective study [97]. In that study, a single plastic stent was re-inserted if a stricture persisted at pancreatography after stent removal within 3 months of the first ERCP.

With respect to FCSEMSs, stents of $6-10 \mathrm{~mm}$ in diameter have been used (Table $6 \mathrm{~s}$ ); the mean stenting duration was 2-6 months and stents were removed uneventfully in 108 (98\%) of 110 patients. (The stent-in-stent technique was used in the two remaining patients and distal FCSEMS migration had occurred in 6 other patients.) Finally, in a pilot study, a biodegradable non-covered self-expandable stent has provided clinical success in 10 of 19 patients (53\%) who had no stricture resolution at least 6 months after plastic stent insertion (median 10 months); adverse events were reported in 4 patients (21\%) [99].

Regarding complications with plastic stents, mild pancreatitis or worsening of pancreatic pain were most commonly reported at short term (average 6.2\%, range $4 \%-39 \%$ ) followed by sepsis, cholangitis, and post-sphincterotomy bleeding (average, $2.6 \%, 2.3 \%$, and $1.5 \%$, respectively) (Table 2 s). Severe pancreatitis has been rarely reported [73]. During follow-up, proximal and distal stent migration is reported in $2.7 \%$ and $3.6 \%$ of cases respectively, and bench tests using a column of water at a pressure lower than that observed in patients with CP $[89,100]$ have shown that almost all stents become obstructed at 3 months. However stent obstruction does not correlate with symptoms $[82,89,100]$. Stent-induced ductal lesions were described in $18 \%$ of patients (range $0-26 \%$ ) and mortality was reported in $0.4 \%(7 / 1620)$ (Table $2 \mathrm{~s})$.

With SEMSs, stent migration $(15 \%-46 \%)$ and de novo strictures $(16 \%-27 \%)$ have also been reported and specific complications include severe pain $(7 \%-20 \%)$ leading to cholestasis and FCSEMS removal (15\%) (Table 6s).

RECOMMENDATION

ESGE recommends performance of endosonographyguided access and drainage of the MPD only in tertiary centers after multidisciplinary discussion and preferably in a research setting.

Strong recommendation, low quality evidence.
Potential indications for endosonography-guided access and drainage of the MPD include patients with symptomatic MPD obstruction and failed conventional transpapillary drainage. Briefly, the technique consists of puncturing the MPD through the gastric or duodenal wall and advancing a guidewire into the MPD to proceed with transpapillary (rendezvous technique) or transmural drainage using a plastic stent [50], or more recently a FCSEMS [101]. It is recognized as one of the most difficult techniques of EUS-guided therapy [102].

Endosonography-guided access and drainage of the MPD has been reported in retrospective, small, single-center studies [103-107] or larger multicenter studies (36 to 80 patients) [108-110] with a follow-up ranging from a few weeks up to 55 months (median 1 year). In all these series, the annual inclusion rate per center was always below 4 , illustrating the rarity of the indications.

Immediate pain relief after successful endosonographyguided access and drainage of the MPD has been reported in a majority of patients with obstructive CP (range 50\%-100\%). In the two series to date with available long-term follow-up, complete or major pain relief was achieved in $70 \%-90 \%$ of patients but the probability of remaining free of pain dropped sharply over time $[108,109]$.

Failed endosonography-guided access and drainage of the MPD occurs in approximately $10 \%$ of cases and the incidence of moderate to severe complications also averages $10 \%$ in the largest series, including severe pancreatitis, perforation, bleeding, and hematoma [103-110]. No procedure-related mortality has been reported. Migration and occlusion of stents necessitating endoscopic re-intervention frequently occur (20\%-55\% of patients).

\section{Pseudocyst management}

Approximately one third of CP patients develop PPC during the course of their disease [36]. PPCs should be differentiated from cystic neoplasms such as potentially malignant mucinous neoplasms, particularly when they present for the first time.

Endoscopic therapy of PPCs consists of inserting a drain from the digestive lumen into the PPC, through the digestive wall ("transmural drainage"), through the papilla ("transpapillary drainage"), or using a combination of these routes. Transpapillary PPC drainage is feasible only if the PPC communicates with the MPD, a situation detected in approximately half of PPCs [111]. Technical and clinical success are usually defined, respectively, as the insertion of at least one stent between the PPC and the digestive lumen (plus removal if indicated) [112], and disappearance of symptoms with complete resolution of the PPC or a decrease in size to less than $2 \mathrm{~cm}$ [113]. 


\section{RECOMMENDATION}

ESGE recommends treating CP-related pseudocysts if they are symptomatic (abdominal pain, gastric outlet obstruction, early satiety, weight loss or jaundice) or present with complications (infection, bleeding, rupture, or fistulization to adjacent hollow structures).

Strong recommendation, low quality evidence.
Spontaneous regression of chronic PPCs is infrequent (0 to $27 \%$ ) and occurs most commonly for PPCs smaller than $4 \mathrm{~cm}$ and/or located within the pancreas [114-115]. The indications for treatment listed above are commonly accepted. In asymptomatic patients with a PPC compressing a major vessel, the risk - benefit ratio of any intervention should be thoroughly analyzed; progressively enlarging collections are considered a valid indication by some authors while others suggest that such patients be followed until symptoms develop [116-117].

\section{RECOMMENDATION}

ESGE recommends endoscopic drainage over percutaneous or surgical treatment for uncomplicated CP-related pseudocysts that are within endoscopic reach.

Strong recommendation, moderate quality evidence.

A meta-analysis of 7 retrospective studies (490 patients with various types of pancreatic fluid collections [PFCs]) found that, compared with percutaneous drainage, endoscopic drainage was associated with a higher clinical success rate, fewer reinterventions, shorter hospital stay, and similar morbidity and recurrence rates [118]. Although percutaneous drainage has mostly been abandoned for the definitive treatment of CPrelated pseudocysts because it often results in an external fistula [119], it may be useful as an emergency measure (e.g., for infected PPC not accessible to endoscopic drainage in a frail patient).

A meta-analysis (5 comparative studies including one RCT, 255 patients) found that, compared with endoscopic therapy, surgery has a higher success rate (odds ratio [OR] $0.43,95 \% \mathrm{Cl}$ $0.20-0.95)$, but is associated with a longer length of hospital stay and higher hospital costs as well as similar rates of morbidity $(18.0 \%$ vs. $11.5 \%)$ and recurrence (3.2\% vs. $3.1 \%)[120]$. A more recent multicenter prospective cohort study (71 patients) reported a similar overall success rate and a shorter hospital stay for endoscopic therapy vs. surgery [121].

\section{RECOMMENDATION}

ESGE suggests MRI with secretin-enhanced magnetic resonance cholangiopancreatography (S-MRCP) for characterizing pancreatic fluid collections and the MPD anatomy before endoscopic drainage of CP-related pseudocysts.

Weak recommendation, low quality evidence.

CT scan, MRI, and EUS allow the characterization of PFCs but the assessment of their solid content is less precise with CT scan [122 -124]; this is important only in subacute PFCs where necrotic debris may impede endoscopic drainage. S-MRCP also allows diagnosis of MPD rupture. This has important consequences for treatment planning: (i) in the absence of MPD rupture, endoscopic drainage can be transmural only; (ii) if a partial MPD rupture is present, insertion of a stent bridging the rupture (as opposed to below it) is associated with treatment success $[63,64]$; and (iii) in the case of a complete MPD rupture (disconnected pancreatic duct syndrome), removal of transmural stents is associated with PFC recurrence so that longterm indwelling of transmural double-pigtail plastic stents should be considered $[125,126]$. Therefore, some centers perform imaging of the MPD by S-MRCP and/or ERCP prior to drainage of and/or stent removal from PFCs.

Although ERCP is still considered to be the gold standard for the diagnosis of MPD disruption, it presents limitations including an accuracy rate of approximately $75 \%$ and adverse events such as infection of a sterile PFC $[127,128]$. In small series, SMRCP showed an accuracy of $>90 \%$ for diagnosing MPD disruption in patients with PFCs $[123,129]$.

These imaging modalities have not been compared for the detection of pseudoaneurysms close to pseudocysts, which is another important consideration when planning treatment.

\section{RECOMMENDATION}

ESGE suggests transpapillary drainage for small (<50 mm) $\mathrm{CP}$-related pseudocysts communicating with the MPD in the head or body of the pancreas and transmural drainage for other CP-related pseudocysts.

Weak recommendation, low quality evidence.

Compared with transmural drainage, transpapillary drainage provides similar success with a similar morbidity rate but fatal or surgical complications are less frequent (1/176 vs. 15/283; $P=0.007)$; however, transpapillary drainage as the only endoscopic therapy has been performed for relatively smaller collections (generally $\leq 50 \mathrm{~mm}$ ) than those managed by transmural drainage alone or combined transpapillary and transmural drainage (Table 7s). If transmural drainage is performed, the addition of transpapillary drainage seems to add no benefit according to a meta-analysis of 9 non-randomized comparative studies (7 including PPCs exclusively, 604 drainage procedures) 
[130]. No definitive conclusion can be drawn as the proportion of patients in whom a transpapillary stent was inserted across as opposed to below a partial MPD disruption, a predictor of success following transpapillary drainage $[131,132]$, was not known. However, this factor may be of marginal importance as the insertion of a stent across a partial MPD rupture succeeds in only $33 \%-67 \%$ of the patients $[131,132]$.

\section{RECOMMENDATION}

ESGE recommends endosonography-guided over conventional access for the transmural drainage of CP-related pseudocysts.

Strong recommendation, moderate quality evidence.

For the transmural drainage of PPCs, a systematic review (four studies, 229 patients) found a higher technical success rate for EUS vs. conventional approach (relative risk [RR] $12.38,95 \% \mathrm{Cl} 1.39-110.22$ ) and no other significant differences (complications, short and long-term clinical success) [133]. The difference in technical success was due to the presence of non-bulging collections which account for approximately half of PFCs [111]; EUS guidance is the only option for transmural drainage in these cases.

\section{RECOMMENDATION}

ESGE suggests the use of double-pigtail plastic stents for the transmural drainage of CP-related pseudocysts; a fully covered biliary SEMS can be considered if disconnected pancreatic duct syndrome has been excluded and indwelling duration is expected to be less than 6 weeks. Weak recommendation, low quality evidence.

Plastic stents are generally used for the transmural drainage of PPCs. Three retrospective studies examined the role of the number or diameter of plastic stents in a total of 307 patients; all studies included patients with various types of PFCs [134136]. Double-pigtail stents of 7-10 Fr were used in the two most recent series as straight stents may migrate and erode large vessels [135]. One study found that the insertion of a single stent was associated with failure of endoscopic therapy (defined as severe procedure-related complication or need for another treatment modality) [135] while two studies found no differences according to the number and diameter of plastic stents $[134,136]$.

Plastic stents and FCSEMSs have been compared for the transmural drainage of PPCs in three meta-analyses $[113,137$, 138]. The two most recent meta-analyses included comparative studies exclusively but only approximately $10 \%$ of patients had CP. These two meta-analyses reported: (i) a similar success and a lower morbidity rate with FCSEMSs vs. plastic stents (OR 0.4, 95\% Cl $0.21-0.73$ ) (three studies, 301 patients)
[138]; and (ii) a higher success rate with FCSEMSs vs. plastic stents (OR 5.35, 95\% Cl 1.35-21.19) (morbidity analysis not reported) (two studies, 250 patients) [113]. Biliary FCSEMSs were used in most patients while lumen-apposing metal stents (LAMSs) were used in 5\% [138] and 6\% of the patients [113]; in the studies that used a standard biliary FCSEMS, a doublepigtail plastic stent was inserted through the FCSEMS to prevent its migration. The older meta-analysis included noncomparative studies only and it found no differences between stents in terms of success rates or morbidity [137].

A meta-analysis ( 6 retrospective studies, 504 patients) compared LAMSs with multiple plastic stents for the treatment of PFCs but only $11 \%$ of patients had a PPC; LAMSs were associated with a higher clinical success rate (RR 2.70, 95\%Cl 1.49$5.00)$ and a lower morbidity rate (RR $0.39,95 \% \mathrm{Cl}, 0.18-0.84$ ) [139]. A decision model analysis concluded that LAMSs were less cost-effective than plastic stents [140].

\section{RECOMMENDATION}

ESGE recommends retrieval of transmural plastic stents at least 6 weeks after pancreatic pseudocyst regression if MPD disruption has been excluded, and long-term indwelling of transmural double-pigtail plastic stents in patients with disconnected pancreatic duct syndrome.

Strong recommendation, low quality evidence.

Transmural plastic stents are generally removed at least 6 weeks after insertion as a retrospective study showed that earlier plastic stent removal was associated with treatment failure [135]. In an RCT (28 patients, 15 of whom had a CP-related $P P C), P F C$ recurred more frequently in patients randomized to stent removal 2 months after drainagevs. no stent removal (38\% vs 0 ); PFC recurrence tended to be associated with MPD rupture as identified at S-MRCP (4/5 vs 2/9, $P=0.063)$ [126].

Disconnected pancreatic duct syndrome generally results from severe necrotizing pancreatitis and has been discussed in a dedicated ESGE Guideline [141]. Retrospective studies have shown that long-term indwelling of double-pigtail transmural plastic stents is effective, with PFC recurrence being uncommon and associated with stent migration $<6$ months after PFC resolution and MPD disruption at the pancreatic head level [142, 143].

With respect to LAMSs, an RCT reported LAMS-related severe adverse events in 6 of 12 patients (50\%), including bleeding, buried stent syndrome, and biliary stricture, all occurring $>3$ weeks after LAMS placement $[144,145]$. Stent-related morbidity dropped to levels similar to those observed with plastic stents after the study protocol was changed to removal of LAMSs within 4 weeks. The placement of a coaxial doublepigtail stent through the LAMS has also been proposed to prevent delayed adverse events [146]. 


\section{RECOMMENDATION}

ESGE recommends the use of endosonographic guidance if the transmural route is selected for draining CP-related pseudocysts in patients with portal hypertension. In the case of arterial pseudoaneurysm close to a CP-related pseudocyst, ESGE recommends arterial embolization prior to endoscopic drainage.

Strong recommendation, low quality evidence.

Extrahepatic portal hypertension develops during the course of CP in $\geq 15 \%$ of patients [147]. The only two series that reported the results of endoscopic drainage for PFCs in patients with portal hypertension used EUS guidance; bleeding was reported in 1 of 26 patients (4\%) [148, 149].

Pseudoaneurysms complicate the course of CP in $1 \%-10 \%$ of patients, mostly those with a PPC, and their rupture is associated with a high mortality [150]. Therefore, some authors recommend embolization of arterial pseudoaneurysms before attempting endoscopic therapy of PPC close to pseudoaneurysms [151]. This strategy has not been tested but, in patients with bleeding pseudoaneurysms, two retrospective series have reported a $94 \%-100 \%$ mid-term success rate with arterial embolization followed by endoscopic therapy of the PPC in a total of 40 patients $[152,153]$.

\section{Biliary strictures}

\section{RECOMMENDATION}

ESGE suggests performance of an ERCP when a CP patient presents with a $\geq 4$-week biliary obstruction (jaundice, asymptomatic elevation of serum alkaline phosphatase [ $>2$ or 3 times the upper limit of normal values] and/or bilirubin) to achieve biliary decompression by means of stent placement. If follow-up shows that the obstruction is caused by a genuine fibrosis rather than transient inflammatory compression, endoscopic stent treatment should be continued in order to dilate the stricture. After 1 year of unsuccessful endotherapy, surgery should be considered.

Weak recommendation, low quality evidence.

Biliary strictures complicate the course of CP in 3\%-23\% of patients, with studies reporting a prevalence as high as $46 \%$ [154]. Symptoms may be absent or include jaundice, cholangitis or choledocholithiasis. Jaundice resolves spontaneously in $20 \%-50 \%$ of patients within 1 month, because of resolution of edema or of a PPC in the head of the pancreas but secondary biliary cirrhosis is relatively frequent $(7.3 \%$ of 288 patients in a review of 11 studies) [154]. Therefore, an asymptomatic elevation of serum alkaline phosphatase ( $>2$ or 3 times the upper limit of normal values) and/or bilirubin for longer than 1 month are usually accepted as an indication for bile duct drainage [155].

As underlined in Section 3, an underlying malignancy should be reasonably excluded.

A single retrospective study compared surgery vs. endoscopic therapy (multiple side-by-side plastic stents or FCSEMS) for the treatment of CP-related biliary strictures in 39 patients [156]. Compared with surgery, endoscopic therapy presented a lower procedural morbidity rate ( $21 \%$ vs. $83 \%$ ) and a lower success rate at 2 years ( $15 \%$ vs. $66 \%$ ). The success rate was noticeably lower than in other studies (Table 8s), including an RCT, maybe because incomplete stricture resolution at ERCP was considered a failure. Outcomes were similar in patients who had surgery as a primary treatment or following unsuccessful endoscopic therapy. The authors proposed to attempt endoscopic therapy first in the absence of associated lesions (e.g., inflammatory cephalic mass), and to evaluate its success after 12 months or three endoscopic procedures.

\section{RECOMMENDATION}

ESGE suggests the temporary insertion of multiple sideby-side plastic stents or of a FCSEMS for treating CP-related benign biliary strictures.

Weak recommendation, moderate quality evidence.

The strategy of endoscopic therapy for benign biliary strictures is detailed in a dedicated ESGE Clinical Guideline [157]; it consists of temporarily dilating the stricture using multiple side-by-side plastic stents or a FCSEMS (single plastic stents or uncovered SEMSs have long been abandoned because of poor long-term results (Table 8s) [158]. An RCT (60 CP patients) found that multiple plastic stents and covered SEMSs provided similar success rates 2 years after stent removal (88.0\% vs. $90.9 \%$, respectively), with similar treatment-related morbidity ( $23.3 \%$ vs. $28.6 \%$, respectively) [159]. The stenting duration was 6 months in both groups. Various stenting durations have not been compared in the literature (scheduled stenting durations with multiple plastic stents and covered SEMSs have generally been for 1 year and for 6-12 months, respectively). Short biliary strictures may respond better than longer ones to stenting, as suggested by a small study (10 CP patients) [160].

\section{RECOMMENDATION}

ESGE recommends maintaining a registry of patients with biliary stents and recalling them for stent removal or exchange.

Strong recommendation, low quality evidence. 
Patient compliance with stent exchange may be poor, giving rise to potentially fatal complications $[161,162]$. To prevent this, various recall systems have proven useful in pilot studies $[163,164]$. Removable FCSEMSs can result in better patient compliance since the number of ERCPs is reduced to two. Of course, patient compliance with repeat interventions should be ensured prior to endoscopic therapy and hepaticojejunostomy remains a valid option for noncompliant patients or if the stricture does not respond to endoscopic therapy.

\section{Disclaimer}

The legal disclaimer for ESGE guidelines [165] applies to the current Guideline.

\section{Acknowledgments}

The authors gratefully acknowledge Dr. Lars Aabakken, GI Endoscopy, OUS-Rikshospitalet University Hospital, Oslo, Norway, and Dr. Kazuo Inui, Department of Gastroenterology, Second Teaching Hospital, Fujita Health University, Nagoya, Japan, for their critical review of the Guideline.

\section{Competing interests}

G. P. Aithal receives consultancy fees from Shire (September 2015 to present), Pfizer (July 2018 to present), and GSK and Agios (February 2018 to present). A. Anderloni has provided consultancy to Boston Scientific (2017-2018). M. J. Bruno has received lecturing and consultancy fees from Boston Scientific, Cook Medical, and Pentax Medical (ongoing) and consultancy fees from Mylan (ongoing); his department is involved in investigator- and industry-initiated studies with Boston Scientific, Cook Medical, and Pentax Medical (ongoing); he is a member (no financial benefit) of the Dutch Pancreatitis Study Group J. Devière receives research support from Olympus for institutional review board-approved studies (ongoing); his department receives research support from Boston Scientific for institutional review board-approved studies (ongoing). J. E. Domínguez-Muñoz has received speaker's honoraria from Boston Scientific (2018); his department has received financial support for educational activities from Pentax and Boston Scientific (2017-2018) and Medtronic (2018). J.-W. Poley receives speaker's fees and travel expenses from Pentax, Boston Scientific, and Cook Endoscopy (ongoing), and consultancy fees from Boston Scientific and Cook Endoscopy (ongoing). A. Sanchez-Yague has provided paid consultancy to Boston Scientific (2015-2018). J. E. van Hooft has received lecture fees from Medtronic (2014-2015) and consultancy fees from Boston Scientific (2014-2016); her department has received research grants from Cook Medical (2014-2018) and Abbott (2014-2017). M. Arvanitakis, P. Cantú, M. Delhaye, J.-M. Dumonceau, S. Lekkerkerker, M. Ramchandani, N. Reddy, A. Tringali, and T. Vaysse have no competing interests.

\section{References}

[1] Dumonceau JM, Delhaye M, Tringali A et al. Endoscopic treatment of chronic pancreatitis: European Society of Gastrointestinal Endoscopy (ESGE) Clinical Guideline. Endoscopy 2012; 44: 784-800

[2] Guyatt G, Oxman AD, Akl EA et al. GRADE guidelines: 1. Introduction - GRADE evidence profiles and summary of findings tables. J Clin Epidemiol 2011; 64: $383-394$

[3] Drewes AM, Bouwense SAW, Campbell CM et al. Guidelines for the understanding and management of pain in chronic pancreatitis. Pancreatology 2017; 17: $720-731$

[4] Romagnuolo J, Talluri J, Kennard E et al. Clinical profile, etiology, and treatment of chronic pancreatitis in North American women: analysis of a large multicenter cohort. Pancreas 2016; 45: 934-940

[5] Díte P, Ruzicka M, Zboril V et al. A prospective, randomized trial comparing endoscopic and surgical therapy for chronic pancreatitis. Endoscopy 2003; 35: $553-558$

[6] Cahen DL, Gouma DJ, Nio Y et al. Endoscopic versus surgical drainage of the pancreatic duct in chronic pancreatitis. N Engl J Med 2007; 356 : $676-684$

[7] Cahen DL, Gouma DJ, Laramée P et al. Long-term outcomes of endoscopic vs surgical drainage of the pancreatic duct in patients with chronic pancreatitis. Gastroenterology 2011; 141: 1690 - 1695

[8] Laramée P, Wonderling D, Cahen DL et al. Trial-based cost-effectiveness analysis comparing surgical and endoscopic drainage in patients with obstructive chronic pancreatitis. BMJ Open 2013; 3: e003676

[9] Dumonceau J-M, Costamagna G, Tringali A et al. Treatment for painful calcified chronic pancreatitis: extracorporeal shock wave lithotripsy versus endoscopic treatment: a randomised controlled trial. Gut 2007; 56: 545 - 552

[10] Jiang L, Ning D, Cheng Q et al. Endoscopic versus surgical drainage treatment of calcific chronic pancreatitis. Int J Surg 2018; 54: 242 247

[11] Sarner M, Cotton PB. Classification of pancreatitis. Gut 1984; 25 : $756-759$

[12] Hookey LC, RioTinto R, Delhaye M et al. Risk factors for pancreatitis after pancreatic sphincterotomy: a review of 572 cases. Endoscopy 2006; 38: $670-676$

[13] Okolo PI, Pasricha PJ, Kalloo AN. What are the long-term results of endoscopic pancreatic sphincterotomy? Gastrointest Endosc 2000; 52: $15-19$

[14] Seza K, Yamaguchi T, Ishihara T et al. A long-term controlled trial of endoscopic pancreatic stenting for treatment of main pancreatic duct stricture in chronic pancreatitis. Hepatogastroenterology 2011; 58 : $2128-2131$

[15] Delhaye M, Arvanitakis M, Verset G et al. Long-term clinical outcome after endoscopic pancreatic ductal drainage for patients with painful chronic pancreatitis. Clin Gastroenterol Hepatol 2004; 2: 1096 - 1106

[16] Tadenuma $\mathrm{H}$, Ishihara T, Yamaguchi T et al. Long-term results of extracorporeal shockwave lithotripsy and endoscopic therapy for pancreatic stones. Clin Gastroenterol Hepatol 2005; 3: 1128-1135

[17] Adamek HE, Jakobs R, Buttmann A et al. Long term follow up of patients with chronic pancreatitis and pancreatic stones treated with extracorporeal shock wave lithotripsy. Gut 1999; 45: $402-405$

[18] Clarke B, Slivka A, Tomizawa Y et al. Endoscopic therapy is effective for patients with chronic pancreatitis. Clin Gastroenterol Hepatol 2012; 10: $795-802$

[19] Seven G, Schreiner MA, Ross AS et al. Long-term outcomes associated with pancreatic extracorporeal shock wave lithotripsy for chronic calcific pancreatitis. Gastrointest Endosc 2012; 75: 997 - 1004.e1 
[20] Hu L-H, Ye B, Yang Y-G et al. Extracorporeal shock wave lithotripsy for Chinese patients with pancreatic stones: a prospective study of 214 cases. Pancreas 2016; 45: 298-305

[21] Kirkegård J, Mortensen FV, Cronin-Fenton D. Chronic pancreatitis and pancreatic cancer risk: a systematic review and meta-analysis. Am J Gastroenterol 2017; 112: 1366-1372

[22] Toft J, Hadden WJ, Laurence JM et al. Imaging modalities in the diagnosis of pancreatic adenocarcinoma: A systematic review and metaanalysis of sensitivity, specificity and diagnostic accuracy. Eur J Radiol 2017; 92: $17-23$

[23] Dimastromatteo J, Brentnall T, Kelly KA. Imaging in pancreatic disease. Nat Rev Gastroenterol Hepatol 2017; 14: 97 - 109

[24] Zhang T-T, Wang L, Liu $\mathrm{H}$ et al. Differentiation of pancreatic carcinoma and mass-forming focal pancreatitis: qualitative and quantitative assessment by dynamic contrast-enhanced MRI combined with diffusion-weighted imaging. Oncotarget 2017; 8: 1744-1759

[25] Niu X, Das S, Bhetuwal A et al. Value of diffusion-weighted imaging in distinguishing pancreatic carcinoma from mass-forming chronic pancreatitis a meta-analysis. Chin Med J 2014; 127: 3477-3482

[26] Fritscher-Ravens A, Brand L, Knöfel WT et al. Comparison of endoscopic ultrasound-guided fine needle aspiration for focal pancreatic lesions in patients with normal parenchyma and chronic pancreatitis. Am J Gastroenterol 2002; 97: 2768 - 2775

[27] Varadarajulu S, Tamhane A, Eloubeidi MA. Yield of EUS-guided FNA of pancreatic masses in the presence or the absence of chronic pancreatitis. Gastrointest Endosc 2005; 62: 728 - 736 quiz 751, 753

[28] Dumonceau J-M, Deprez PH, Jenssen C et al. Indications, results, and clinical impact of endoscopic ultrasound (EUS)-guided sampling in gastroenterology: European Society of Gastrointestinal Endoscopy (ESGE) Clinical Guideline - Updated January 2017. Endoscopy 2017; 49: $695-714$

[29] Polkowski M, Jenssen C, Kaye P et al. Technical aspects of endoscopic ultrasound (EUS)-guided sampling in gastroenterology: European Society of Gastrointestinal Endoscopy (ESGE) Technical Guideline March 2017. Endoscopy 2017; 49: 989-1006

[30] Ohyama H, Mikata R, Ishihara T et al. Efficacy of stone density on noncontrast computed tomography in predicting the outcome of extracorporeal shock wave lithotripsy for patients with pancreatic stones. Pancreas 2015; 44: $422-428$

[31] Anaizi A, Hart PA, Conwell DL. Diagnosing chronic pancreatitis. Dig Dis Sci 2017; 62: $1713-1720$

[32] Anderson SW, Soto JA. Pancreatic duct evaluation: accuracy of portal venous phase $64 \mathrm{MDCT}$. Abdom Imaging 2009; 34: 55-63

[33] Kolodziejczyk E, Jurkiewicz E, Pertkiewicz J et al. MRCP versus ERCP in the evaluation of chronic pancreatitis in children: which is the better choice? Pancreas 2016; 45: 1115-1119

[34] Sica GT, Braver J, Cooney M] et al. Comparison of endoscopic retrograde cholangiopancreatography with MR cholangiopancreatography in patients with pancreatitis. Radiology 1999; 210: 605-610

[35] Sarles H, Camarena J, Gomez-Santana C. Radiolucent and calcified pancreatic lithiasis: two different diseases. Role of alcohol and heredity. Scand J Gastroenterol 1992; 27: 71-76

[36] Ammann RW, Akovbiantz A, Largiader F et al. Course and outcome of chronic pancreatitis. Longitudinal study of a mixed medical-surgical series of 245 patients. Gastroenterology 1984; 86: 820-828

[37] Frulloni L, Gabbrielli A, Pezzilli R et al. Chronic pancreatitis: report from a multicenter Italian survey (PanCrolnfAISP) on 893 patients. Dig Liver Dis 2009; 41: 311 -317

[38] Delhaye M, Vandermeeren A, Baize M et al. Extracorporeal shockwave lithotripsy of pancreatic calculi. Gastroenterology 1992; 102: $610-620$
[39] Moole H, Jaeger A, Bechtold ML et al. Success of extracorporeal shockwave lithotripsy in chronic calcific pancreatitis management: a meta-analysis and systematic review. Pancreas 2016; 45: 651-658

[40] Farnbacher M], Schoen C, Rabenstein T et al. Pancreatic duct stones in chronic pancreatitis: criteria for treatment intensity and success. Gastrointest Endosc 2002; 56: 501-506

[41] Suzuki Y, Sugiyama M, Inui K et al. Management for pancreatolithiasis: a Japanese multicenter study. Pancreas 2013; 42: 584-588

[42] Inui K, Masamune A, Igarashi Y et al. Management of pancreatolithiasis: a nationwide survey in Japan. Pancreas 2018; 47: 708 - 714

[43] Sherman S, Lehman GA, Hawes RH et al. Pancreatic ductal stones: frequency of successful endoscopic removal and improvement in symptoms. Gastrointest Endosc 1991; 37: $511-517$

[44] Thomas M, Howell DA, Carr-Locke D et al. Mechanical lithotripsy of pancreatic and biliary stones: complications and available treatment options collected from expert centers. Am J Gastroenterol 2007; 102: $1896-1902$

[45] Dumonceau JM, Devière J, Le Moine O et al. Endoscopic pancreatic drainage in chronic pancreatitis associated with ductal stones: longterm results. Gastrointest Endosc 1996; 43: 547 - 555

[46] Tandan M, Reddy DN, Talukdar R et al. Long-term clinical outcomes of extracorporeal shockwave lithotripsy in painful chronic calcific pancreatitis. Gastrointest Endosc 2013; 78: 726-733

[47] Vaysse T, Boytchev I, Antoni G et al. Efficacy and safety of extracorporeal shock wave lithotripsy for chronic pancreatitis. Scand J Gastroenterol 2016; 51: 1380 - 1385

[48] Ohara H, Hoshino M, Hayakawa T et al. Single application extracorporeal shock wave lithotripsy is the first choice for patients with pancreatic duct stones. Am J Gastroenterol 1996; 91: 1388-1394

[49] Inui K, Tazuma S, Yamaguchi T et al. Treatment of pancreatic stones with extracorporeal shock wave lithotripsy: results of a multicenter survey. Pancreas 2005; 30: 26-30

[50] Nguyen-Tang T, Dumonceau J-M. Endoscopic treatment in chronic pancreatitis, timing, duration and type of intervention. Best Pract Res Clin Gastroenterol 2010; 24: 281 - 298

[51] Kondo H, Naitoh I, Ohara H et al. Efficacy of pancreatic stenting prior to extracorporeal shock wave lithotripsy for pancreatic stones. Dig Liver Dis 2014; 46: 639-644

[52] Tandan M, Reddy DN, Santosh D et al. Extracorporeal shock wave lithotripsy and endotherapy for pancreatic calculi-a large single center experience. Indian J Gastroenterol 2010; 29: 143-148

[53] Brand B, Kahl M, Sidhu S et al. Prospective evaluation of morphology, function, and quality of life after extracorporeal shockwave lithotripsy and endoscopic treatment of chronic calcific pancreatitis. Am J Gastroenterol 2000; 95: 3428-3438

[54] Korpela T, Udd M, Tenca A et al. Long-term results of combined ESWL and ERCP treatment of chronic calcific pancreatitis. Scand J Gastroenterol 2016; 51: 866-871

[55] Choi EK, McHenry L, Watkins JL et al. Use of intravenous secretin during extracorporeal shock wave lithotripsy to facilitate endoscopic clearance of pancreatic duct stones. Pancreatology 2012; 12: 272 275

[56] Merrill JT, Mullady DK, Early DS et al. Timing of endoscopy after extracorporeal shock wave lithotripsy for chronic pancreatitis. Pancreas 2011; 40: $1087-1090$

[57] Li B-R, Liao Z, Du T-T et al. Extracorporeal shock wave lithotripsy is a safe and effective treatment for pancreatic stones coexisting with pancreatic pseudocysts. Gastrointest Endosc 2016; 84: 69-78

[58] Li B-R, Liao Z, Du T-T et al. Risk factors for complications of pancreatic extracorporeal shock wave lithotripsy. Endoscopy 2014; 46: 1092 1100 
[59] Delhaye M. Extracorporeal shock wave lithotripsy for pancreatic stones - UpToDate. Accessed June 5 2018. https://www.uptodate. com/contents/extracorporeal-shock-wave-lithotripsy-for-pancreaticstones? search $=$ ESWL\%20pancreas\&source $=$ search_result\&selectedTitle $=1 \sim 150 \&$ usage_type $=$ default\&display_rank $=1$

[60] Crossley GH, Poole JE, Rozner MA et al. The Heart Rhythm Society (HRS)/American Society of Anesthesiologists (ASA) expert consensus statement on the perioperative management of patients with implantable defibrillators, pacemakers and arrhythmia monitors: facilities and patient management. Heart Rhythm 2011; 8: 1114-1154

[61] Beyna T, Neuhaus H, Gerges C. Endoscopic treatment of pancreatic duct stones under direct vision: Revolution or resignation? Systematic review. Dig Endosc 2018; 30: 29-37

[62] Attwell AR, Brauer BC, Chen YK et al. Endoscopic retrograde cholangiopancreatography with per oral pancreatoscopy for calcific chronic pancreatitis using endoscope and catheter-based pancreatoscopes: a 10-year single-center experience. Pancreas 2014; 43: 268 - 274

[63] Delhaye M, Matos C, Devière J. Endoscopic management of chronic pancreatitis. Gastrointest Endosc Clin N Am 2003; 13: 717- 742

[64] Kwon C-I, Gromski MA, Sherman S et al. Clinical response to dorsal duct drainage via the minor papilla in refractory obstructing chronic calcific pancreatitis. Endoscopy 2017; 49: 371 - 377

[65] Smits ME, Badiga SM, Rauws EA et al. Long-term results of pancreatic stents in chronic pancreatitis. Gastrointest Endosc 1995; 42: 461 467

[66] Eleftheriadis N, Dinu F, Delhaye M et al. Long-term outcome after pancreatic stenting in severe chronic pancreatitis. Endoscopy 2005; 37: $223-230$

[67] Ponchon T, Bory RM, Hedelius F et al. Endoscopic stenting for pain relief in chronic pancreatitis: results of a standardized protocol. Gastrointest Endosc 1995; 42: $452-456$

[68] Cremer M, Devière J, Delhaye $M$ et al. Stenting in severe chronic pancreatitis: results of medium-term follow-up in seventy-six patients. Endoscopy 1991; 23: 171-176

[69] Ishihara T, Yamaguchi T, Seza K et al. Efficacy of s-type stents for the treatment of the main pancreatic duct stricture in patients with chronic pancreatitis. Scand J Gastroenterol 2006; 41: 744 - 750

[70] Topazian M, Aslanian H, Andersen D. Outcome following endoscopic stenting of pancreatic duct strictures in chronic pancreatitis. I Clin Gastroenterol 2005; 39: 908 - 911

[71] Jafri M, Javed S, Sachdev A et al. Efficacy of endotherapy in the treatment of pain associated with chronic pancreatitis: a systematic review and meta-analysis. JOP 2017; 18: 125-132

[72] Binmoeller KF, Jue P, Seifert $\mathrm{H}$ et al. Endoscopic pancreatic stent drainage in chronic pancreatitis and a dominant stricture: long-term results. Endoscopy 1995; 27: 638-644

[73] Farnbacher M], Mühldorfer S, Wehler M et al. Interventional endoscopic therapy in chronic pancreatitis including temporary stenting: a definitive treatment? Scand J Gastroenterol 2006; 41: 111-117

[74] Sasahira N, Tada M, Isayama $\mathrm{H}$ et al. Outcomes after clearance of pancreatic stones with or without pancreatic stenting. J Gastroenterol 2007; 42: 63-69

[75] Costamagna G, Bulajic M, Tringali A et al. Multiple stenting of refractory pancreatic duct strictures in severe chronic pancreatitis: longterm results. Endoscopy 2006; 38: 254-259

[76] Bove V, Tringali A, Valerii G et al. Endoscopic dilation of pancreatic duct strictures in chronic pancreatitis with multiple plastic stents: results in 48 patients. Gastrointest Endosc 2017; 85: AB236

[77] Eisendrath P, Devière J. Expandable metal stents for benign pancreatic duct obstruction. Gastrointest Endosc Clin N Am 1999; 9: 547 - 554

[78] Shen Y, Liu M, Chen M et al. Covered metal stent or multiple plastic stents for refractory pancreatic ductal strictures in chronic pancreatitis: a systematic review. Pancreatology 2014; 14: 87-90
[79] Matsubara S, Sasahira N, Isayama H et al. Prospective pilot study of fully covered self-expandable metal stents for refractory benign pancreatic duct strictures: long-term outcomes. Endosc Int Open 2016; 4: E1215-E1222

[80] Oh D, Lee JH, Song TJ et al. Long-term outcomes of 6-mm diameter fully covered self-expandable metal stents in benign refractory pancreatic ductal stricture. Dig Endosc 2018; 30: 508 - 515

[81] Tringali A, Vadalà di Prampero SF, Landi R et al. Fully covered self-expandable metal stents to dilate persistent pancreatic strictures in chronic pancreatitis: long-term follow-up from a prospective study. Gastrointest Endosc 2018; 88: 939-946

[82] Morgan DE, Smith JK, Hawkins K et al. Endoscopic stent therapy in advanced chronic pancreatitis: relationships between ductal changes, clinical response, and stent patency. Am J Gastroenterol 2003; 98: $821-826$

[83] Johanson JF, Schmalz M], Geenen JE. Incidence and risk factors for biliary and pancreatic stent migration. Gastrointest Endosc 1992; 38: $341-346$

[84] Rösch T, Daniel S, Scholz M et al. Endoscopic treatment of chronic pancreatitis: a multicenter study of 1000 patients with long-term follow-up. Endoscopy 2002; 34: 765 - 771

[85] Kawaguchi Y, Lin J-C, Kawashima Y et al. Risk factors for migration, fracture, and dislocation of pancreatic stents. Gastroenterol Res Pract 2015; 2015: 365457

[86] Kim MH, Myung SJ, Kim YS et al. Routine biliary sphincterotomy may not be indispensable for endoscopic pancreatic sphincterotomy. Endoscopy 1998; 30: 697-701

[87] Weber A, Schneider ], Neu B et al. Endoscopic stent therapy for patients with chronic pancreatitis: results from a prospective follow-up study. Pancreas 2007; 34: $287-294$

[88] Vitale GC, Cothron K, Vitale EA et al. Role of pancreatic duct stenting in the treatment of chronic pancreatitis. Surg Endosc 2004; 18: $1431-1434$

[89] Farnbacher M], Radespiel-Tröger M, König MD et al. Pancreatic endoprostheses in chronic pancreatitis: criteria to predict stent occlusion. Gastrointest Endosc 2006; 63: 60-66

[90] He Y-X, Xu H-W, Sun X-T et al. Endoscopic management of early-stage chronic pancreatitis based on M-ANNHEIM classification system: a prospective study. Pancreas 2014; 43: 829-833

[91] Kim CH, Bang S, Song KH et al. Analysis of the effects of stent insertion and the factors related to stent retrieval in chronic pancreatitis accompanying main pancreatic duct obstruction. Gut Liver 2007; 1 : 063-067

[92] Boursier J, Quentin V, Le Tallec V et al. Endoscopic treatment of painful chronic pancreatitis: Evaluation of a new flexible multiperforated plastic stent. Gastroenterol Clin Biol 2008; 32: 801 - 805

[93] Mangiavillano B, Pagano N, Baron TH et al. Biliary and pancreatic stenting: Devices and insertion techniques in therapeutic endoscopic retrograde cholangiopancreatography and endoscopic ultrasonography. World J Gastrointest Endosc 2016; 8: 143-156

[94] Dumonceau JM, Heresbach D, Devière J et al. Biliary stents: models and methods for endoscopic stenting. Endoscopy 2011; 43: 617-626

[95] Buscaglia JM, DiMaio C], Pollack MJ et al. Are large side holes associated with reduced rates of pancreatic stent occlusion? Results of a prospective study JOP 2009; 10: $496-500$

[96] Sauer BG, Gurka M], Ellen K et al. Effect of pancreatic duct stent diameter on hospitalization in chronic pancreatitis: does size matter? Pancreas 2009; 38: 728-731

[97] Hirota M, Asakura T, Kanno A et al. Long-period pancreatic stenting for painful chronic calcified pancreatitis required higher medical costs and frequent hospitalizations compared with surgery. Pancreas 2011; 40: $946-950$ 
[98] Weber A, Schneider J, Neu B et al. Endoscopic stent therapy in patients with chronic pancreatitis: a 5-year follow-up study. World J Gastroenterol 2013; 19: 715-720

[99] Cahen DL, Van der Merwe SW, Laleman W et al. A biodegradable noncovered self-expandable stent to treat pancreatic duct strictures in chronic pancreatitis: a proof of principle. Gastrointest Endosc 2018; 87: $486-491$

[100] Ikenberry SO, Sherman S, Hawes RH et al. The occlusion rate of pancreatic stents. Gastrointest Endosc 1994; 40: 611-613

[101] Oh D, Park DH, Cho MK et al. Feasibility and safety of a fully covered self-expandable metal stent with antimigration properties for EUSguided pancreatic duct drainage: early and midterm outcomes (with video). Gastrointest Endosc 2016; 83: 366 - 373.e2

[102] Deviere J. EUS-guided pancreatic duct drainage: a rare indication in need of prospective evidence. Gastrointest Endosc 2017; 85: 178 180

[103] François E, Kahaleh M, Giovannini M et al. EUS-guided pancreaticogastrostomy. Gastrointest Endosc 2002; 56: 128-133

[104] Mallery S, Matlock J, Freeman ML. EUS-guided rendezvous drainage of obstructed biliary and pancreatic ducts: Report of 6 cases. Gastrointest Endosc 2004; 59: 100 - 107

[105] Will U, Fueldner F, Thieme A-K et al. Transgastric pancreatography and EUS-guided drainage of the pancreatic duct. J Hepatobil Pancreat Surg 2007; 14: $377-382$

[106] Kahaleh M, Hernandez A], Tokar J et al. EUS-guided pancreaticogastrostomy: analysis of its efficacy to drain inaccessible pancreatic ducts. Gastrointest Endosc 2007; 65: 224-230

[107] Brauer BC, Chen YK, Fukami N et al. Single-operator EUS-guided cholangiopancreatography for difficult pancreaticobiliary access (with video). Gastrointest Endosc 2009; 70: 471 - 479

[108] Tessier G, Bories E, Arvanitakis M et al. EUS-guided pancreatogastrostomy and pancreatobulbostomy for the treatment of pain in patients with pancreatic ductal dilatation inaccessible for transpapillary endoscopic therapy. Gastrointest Endosc 2007; 65: 233-241

[109] Tyberg A, Sharaiha RZ, Kedia P et al. EUS-guided pancreatic drainage for pancreatic strictures after failed ERCP: a multicenter international collaborative study. Gastrointest Endosc 2017; 85: 164-169

[110] Chen Y-I, Levy M], Moreels TG et al. An international multicenter study comparing EUS-guided pancreatic duct drainage with enteroscopy-assisted endoscopic retrograde pancreatography after Whipple surgery. Gastrointest Endosc 2017; 85: 170-177

[111] Barthet M, Lamblin G, Gasmi M et al. Clinical usefulness of a treatment algorithm for pancreatic pseudocysts. Gastrointest Endosc 2008; 67: $245-252$

[112] Shah RJ, Shah JN, Waxman I et al. Safety and efficacy of endoscopic ultrasound-guided drainage of pancreatic fluid collections with lumen-apposing covered self-expanding metal stents. Clin Gastroenterol Hepatol 2015; 13: 747-752

[113] Yoon SB, Lee IS, Choi MG. Metal versus plastic stents for drainage of pancreatic fluid collection: A meta-analysis. United European Gastroenterol ] 2018; 6: 729-738

[114] Andrén-Sandberg A, Dervenis C. Pancreatic pseudocysts in the 21st century. Part II: natural history. JOP 2004; 5: $64-70$

[115] Gouyon B, Lévy P, Ruszniewski P et al. Predictive factors in the outcome of pseudocysts complicating alcoholic chronic pancreatitis. Gut 1997; 41: $821-825$

[116] Lerch MM, Stier A, Wahnschaffe U et al. Pancreatic pseudocysts: observation, endoscopic drainage, or resection? Dtsch Arztebl Int 2009; 106: 614-621

[117] Law R, Baron TH. Endoscopic management of pancreatic pseudocysts and necrosis. Expert Rev Gastroenterol Hepatol 2015; 9: 167 175
[118] Khan M, Hammad T, Khan Z et al. Endoscopic versus percutaneous management for symptomatic pancreatic fluid collections: a systematic review and meta-analysis. Endosc Int Open 2018; 06: E474E483

[119] Nealon WH, Walser E. Main pancreatic ductal anatomy can direct choice of modality for treating pancreatic pseudocysts (surgery versus percutaneous drainage). Ann Surg 2002; 235: 751 - 758

[120] Zhao X, Feng T, Ji W. Endoscopic versus surgical treatment for pancreatic pseudocyst. Dig Endosc 2016; 28: 83-91

[121] Redwan AA, Hamad MA, Omar MA. Pancreatic pseudocyst dilemma: cumulative multicenter experience in management using endoscopy, laparoscopy, and open surgery. J Laparoendosc Adv Surg Tech A 2017; 27: $1022-1030$

[122] Morgan DE, Baron TH, Smith JK et al. Pancreatic fluid collections prior to intervention: evaluation with MR imaging compared with CT and US. Radiology 1997; 203: 773-778

[123] Kamal A, Singh VK, Akshintala VS et al. CT and MRI assessment of symptomatic organized pancreatic fluid collections and pancreatic duct disruption: an interreader variability study using the revised Atlanta classification 2012. Abdom Imaging 2015; 40: 1608-1616

[124] Rana SS, Chaudhary V, Sharma R et al. Comparison of abdominal ultrasound, endoscopic ultrasound and magnetic resonance imaging in detection of necrotic debris in walled-off pancreatic necrosis. Gastroenterol Rep (Oxf) 2016; 4: 50 - 53

[125] Bang JY, Wilcox CM, Trevino J et al. Factors impacting treatment outcomes in the endoscopic management of walled-off pancreatic necrosis. J Gastroenterol Hepatol 2013; 28: 1725-1732

[126] Arvanitakis M, Delhaye M, Bali MA et al. Pancreatic-fluid collections: a randomized controlled trial regarding stent removal after endoscopic transmural drainage. Gastrointest Endosc 2007; 65: 609619

[127] Gillams AR, Kurzawinski T, Lees WR. Diagnosis of duct disruption and assessment of pancreatic leak with dynamic secretin-stimulated MR cholangiopancreatography. AJR Am J Roentgenol 2006; 186: 499 506

[128] Costamagna G, Mutignani M, Ingrosso M et al. Endoscopic treatment of postsurgical external pancreatic fistulas. Endoscopy 2001; 33: $317-322$

[129] Drake LM, Anis M, Lawrence C. Accuracy of magnetic resonance cholangiopancreatography in identifying pancreatic duct disruption. J Clin Gastroenterol 2012; 46: 696-699

[130] Amin S, Yang DJ, Lucas AL et al. There Is no advantage to transpapillary pancreatic duct stenting for the transmural endoscopic drainage of pancreatic fluid collections: a meta-analysis. Clin Endosc 2017; 50: $388-394$

[131] Telford JJ, Farrell JJ, Saltzman JR et al. Pancreatic stent placement for duct disruption. Gastrointest Endosc 2002; 56: 18-24

[132] Varadarajulu S, Noone TC, Tutuian R et al. Predictors of outcome in pancreatic duct disruption managed by endoscopic transpapillary stent placement. Gastrointest Endosc 2005; 61: 568 - 575

[133] Panamonta N, Ngamruengphong S, Kijsirichareanchai K et al. Endoscopic ultrasound-guided versus conventional transmural techniques have comparable treatment outcomes in draining pancreatic pseudocysts. Eur J Gastroenterol Hepatol 2012; 24: 1355-1362

[134] Bang JY, Wilcox CM, Trevino JM et al. Relationship between stent characteristics and treatment outcomes in endoscopic transmural drainage of uncomplicated pancreatic pseudocysts. Surg Endosc 2014; 28: $2877-2883$

[135] Cahen D, Rauws E, Fockens P et al. Endoscopic drainage of pancreatic pseudocysts: long-term outcome and procedural factors associated with safe and successful treatment. Endoscopy 2005; 37: $977-983$ 
[136] Lin H, Zhan X-B, Sun S-Y et al. Stent selection for endoscopic ultrasound-guided drainage of pancreatic fluid collections: a multicenter study in China. Gastroenterol Res Pract 2014; 2014: 193562

[137] Bang JY, Hawes R, Bartolucci A et al. Efficacy of metal and plastic stents for transmural drainage of pancreatic fluid collections: A systematic review. Dig Endosc 2015; 27: 486-498

[138] Panwar R, Singh PM. Efficacy and safety of metallic stents in comparison to plastic stents for endoscopic drainage of peripancreatic fluid collections: a meta-analysis and trial sequential analysis. Clin J Gastroenterol 2017; 10: 403-414

[139] Hammad T, Khan MA, Alastal Y et al. Efficacy and safety of lumenapposing metal stents in management of pancreatic fluid collections: are they better than plastic stents? a systematic review and meta-analysis Dig Dis Sci 2018; 63: 289-301

[140] Chen Y-I, Khashab MA, Adam V et al. A cost-effectiveness analysis comparing lumen apposing metal stents with plastic stents in the management of pancreatic pseudocysts. Gastroenterology 2017; 152: $\mathrm{S} 132$

[141] Arvanitakis M, Dumonceau J-M, Albert J et al. Endoscopic management of acute necrotizing pancreatitis: European Society of Gastrointestinal Endoscopy (ESGE) evidence-based multidisciplinary guidelines. Endoscopy 2018; 50: 524-546

[142] Téllez-Aviña FI, Casasola-Sánchez LE, Ramírez-Luna MÁ et al. Permanent indwelling transmural stents for endoscopic treatment of patients with disconnected pancreatic duct syndrome: long-term results. J Clin Gastroenterol 2018; 52: 85-90

[143] Rana SS, Bhasin DK, Sharma R et al. Factors determining recurrence of fluid collections following migration of intended long term transmural stents in patients with walled off pancreatic necrosis and disconnected pancreatic duct syndrome. Endosc Ultrasound 2015; 4: $208-212$

[144] Bang JY, Hasan M, Navaneethan U et al. Lumen-apposing metal stents (LAMS) for pancreatic fluid collection (PFC) drainage: may not be business as usual. Gut 2017; 66: $2054-2056$

[145] Bang JY, Navaneethan U, Hasan MK et al. Non-superiority of lumenapposing metal stents over plastic stents for drainage of walled-off necrosis in a randomised trial. Gut 2018: doi:10.1136/gutjnl-2017315335

[146] Puga M, Consiglieri C, Busquets J et al. Safety of lumen-apposing stent with or without coaxial plastic stent for endoscopic ultrasound-guided drainage of pancreatic fluid collections: a retrospective study. Endoscopy 2018; 10: 1022-1026

[147] Bernades P, Baetz A, Lévy P et al. Splenic and portal venous obstruction in chronic pancreatitis. A prospective longitudinal study of a medical-surgical series of 266 patients. Dig Dis Sci 1992; 37: 340 346

[148] Sriram PV, Kaffes AJ, Rao GV et al. Endoscopic ultrasound-guided drainage of pancreatic pseudocysts complicated by portal hypertension or by intervening vessels. Endoscopy 2005; 37: 231 - 235

[149] Rana SS, Sharma R, Ahmed SU et al. Endoscopic ultrasound-guided transmural drainage of walled-off pancreatic necrosis in patients with portal hypertension and intra-abdominal collaterals. Indian J Gastroenterol 2017; 36: 400-404
[150] Evans RP, Mourad MM, Pall G et al. Pancreatitis: Preventing catastrophic haemorrhage. World J Gastroenterol 2017; 23: 5460-5468

[151] Delhaye M, Matos C, Deviere J. Endoscopic technique for the management of pancreatitis and its complications. Best Pract Res Clin Gastroenterol 2004; 18: 155-181

[152] Rana SS, Kumar A, Lal A et al. Safety and efficacy of angioembolisation followed by endoscopic ultrasound guided transmural drainage for pancreatic fluid collections associated with arterial pseudoaneurysm. Pancreatology 2017; 17: 658-662

[153] Nykänen T, Udd M, Peltola EK et al. Bleeding pancreatic pseudoaneurysms: management by angioembolization combined with therapeutic endoscopy. Surg Endosc 2017; 31: $692-703$

[154] Abdallah AA, Krige JE], Bornman PC. Biliary tract obstruction in chronic pancreatitis. HPB (Oxford) 2007; 9: 421-428

[155] Frey CF, Suzuki M, Isaji S. Treatment of chronic pancreatitis complicated by obstruction of the common bile duct or duodenum. World Surg 1990; 14: 59-69

[156] Regimbeau J-M, Fuks D, Bartoli E et al. A comparative study of surgery and endoscopy for the treatment of bile duct stricture in patients with chronic pancreatitis. Surg Endosc 2012; 26: 2902-2908

[157] Dumonceau J-M, Tringali A, Papanikolaou I et al. Endoscopic biliary stenting: indications, choice of stents, and results: European Society of Gastrointestinal Endoscopy (ESGE) Clinical Guideline - Updated October 2017. Endoscopy 2018; 50: 910 - 930

[158] Siriwardana HPP, Siriwardena AK. Systematic appraisal of the role of metallic endobiliary stents in the treatment of benign bile duct stricture. Ann Surg 2005; 242: 10 - 19

[159] Haapamäki C, Kylänpää L, Udd M et al. Randomized multicenter study of multiple plastic stents vs. covered self-expandable metallic stent in the treatment of biliary stricture in chronic pancreatitis. Endoscopy 2015; 47: 605-610

[160] Ohyama H, Mikata R, Ishihara T et al. Efficacy of multiple biliary stenting for refractory benign biliary strictures due to chronic calcifying pancreatitis. World J Gastrointest Endosc 2017; 9: 12-18

[161] Pozsár J, Sahin P, László F et al. Medium-term results of endoscopic treatment of common bile duct strictures in chronic calcifying pancreatitis with increasing numbers of stents. J Clin Gastroenterol 2004; 38: $118-123$

[162] Kiehne K, Fölsch UR, Nitsche R. High complication rate of bile duct stents in patients with chronic alcoholic pancreatitis due to noncompliance. Endoscopy 2000; 32: 377-380

[163] Gu Y, Wang L, Zhao L et al. Effect of mobile phone reminder messages on adherence of stent removal or exchange in patients with benign pancreaticobiliary diseases: a prospectively randomized, controlled study. BMC Gastroenterol 2016; 16: 105

[164] Ooi M, Liu K, Sanagapalli S et al. The effects of a biliary stent registry on complications related to biliary stenting. Gastrointest Endosc 2015; 81: AB398

[165] Dumonceau JM, Hassan C, Riphaus A et al. European Society of Gastrointestinal Endoscopy (ESGE) Guideline Development Policy. Endoscopy 2012; 44: 626-629 